\title{
Outcome of Immediate Management in Chemical Ocular Burns
}

\author{
Shreya Thatte ${ }^{1 *}$, Garima Tiwari ${ }^{2}$ \\ ${ }^{1}$ Professor and Head, Department of Ophthalmology, Sri Aurobindo Medical College and PG Institute, Indore, \\ India \\ ${ }^{2}$ Junior Resident, Department of Ophthalmology, Sri Aurobindo Medical College and PG Institute, Indore, India \\ *Corresponding Author: Shreya Thatte, Professor and Head, Department of Ophthalmology, Sri Aurobindo \\ Medical College and PG Institute, Indore, India; Email: shreyathatte@gmail.com
}

Received Date: 20-08-2021; Accepted Date: 15-09-2021; Published Date: 22-09-2021

Copyright $^{\oplus} 2021$ by Thatte $S$, et al. All rights reserved. This is an open access article distributed under the terms of the Creative Commons Attribution License, which permits unrestricted use, distribution, and reproduction in any medium, provided the original author and source are credited.

\begin{abstract}
Purpose: To evaluate the outcome of immediate management in acute ocular chemical burns.

Methods: 29 eyes of 19 patients with acute chemical burns were studied. All patients received immediate first aid. Limbal and conjunctival involvement were graded as per Dua's classification. $86.8 \%$ patients with grade 1, 2 and 3 were managed conservatively while amniotic membrane transplantation was performed in $13.7 \%$ of patients who had grade 4 or grade 5 involvement. All patients were followed up for a period of 6 months.

Results: $73.6 \%$ patients presented with alkali burns while $26.3 \%$ patients presented with acid burns. 3.4\% eyes had grade I involvement, $55.1 \%$ eyes had grade II, $27.5 \%$ eyes had grade III, $3.4 \%$ eyes had grade IV and 3.4\% had grade V involvement. Of 29 eyes, $86 \%$ showed epithelialization by 8 weeks, and rest $13.7 \%$ showed complete epithelialization by 4 months. On long term follow-up, complications were seen in $13.6 \%$ eyes. Symblepharon occurred in $6.8 \%$ eyes and rest $6.8 \%$ eyes developed corneal vascularization due to secondary limbal stem cell deficiency. None of the eyes showed worsening signs of corneal thinning and perforation.

Conclusions: Immediate intervention in acute ocular burns, in the form of medical or surgical, prevents further ocular surface damage, promotes wound healing, and hinders visually debilitating cicatricial sequelae. In our experience, surgical intervention in patients with Grade 4 involvement and above leads to early rehabilitation and gain of visual function.
\end{abstract}




\section{Keywords}

Ocular Chemical Injury; Intraocular Pressure; Ophthalmology; Visual Acuity

\section{Introduction}

Ocular chemical injury remains one of the most challenging ocular emergencies to manage. These injuries can be acid and alkaline burns, requiring immediate treatment to avoid complications in the form of chronic ocular surface disease, Limbal Stem Cell Deficiency (LSCD), Persistent Epithelial Defects (PED), scarring, glaucoma, cataract, dry eye, symblepharon formation, forniceal shortening, persistent inflammation, chronic pain and reduced Visual Acuity (VA) and permanent loss of vision [1]. Any accompanying lid burns can cause lid abnormalities often resulting in exposure keratopathy and mechanical injury to the cornea and are usually associated with a poor prognosis [2]. The prognosis depends on the severity of the original injury and on the rapidity and mode of treatment, which is very well described by Dua 's classification as it provides a more accurate grading of ocular surface burns that would allow for a more precise prediction of clinical outcomes [3]. Thus, immediate management of acute chemical injury is essential to avoid the most dreaded sight threatening complication [3]. Henceforth, in this retrospective cohort study, we have analyzed the morphological and functional outcomes after acute ocular chemical burn and correlated with the degree of injury and treatment strategy. Particularly, we focused on understanding the course of the disease.

\section{Material and Methods}

We analyzed data from 29 eyes of 19 patients treated for acute ocular chemical burns between 2019 and 2020. Since being a true ocular emergency, without a prior detailed history, all patients received first-aid therapy consisting of measurement of $\mathrm{pH}$ at presentation to identify whether it is an alkali injury or an acid injury, with a litmus paper followed by extensive irrigation of the injured eye with normal saline $(0.9 \%)$ at room temperature. Irrigation was continued until normalization of $\mathrm{pH}$ was confirmed. Even if the history was suggestive of unilateral injury, the $\mathrm{pH}$ of both eyes was checked. Eversion of the eyelids and sweeping of the fornices was implemented for identifying and removing any hidden precipitates. General systemic examination was carried out to inspect any other site of burn on the body. After the first aid, a detailed history regarding the chemical agent, nature of chemical, with present clinical complaints was noted. Ophthalmic examination included measuring visual acuity, Intraocular Pressure (IOP) by Noncontact Tonometer (NCT) and a detailed slit lamp examination was carried out to examine the adnexal, ocular surface and anterior segment. Posterior segment was examined wherever possible and B-scan ultrasound was done for any evidence of posterior segment involvement. On the basis of limbal and conjunctival

Thatte S | Volume 2; Issue 3 (2021) | JOAR-2(3)-020 | Research Article

Citation: Thatte S, et al. Outcome of Immediate Management in Chemical Ocular Burns. J Ophthalmol Adv Res. 2021;2(3):1-13.

DOI: http://dx.doi.org/10.46889/JOAR.2021.2301 
involvement, each patient was graded according to Dua's classification. All patients received regimen of topical eye drops including prednisolone acetate $1 \%$ every 2 hours, ascorbic acid $10 \%$ every 2 hours in alkali burn specially, moxifloxacin $0.5 \% 4$ times daily, atropine eye drop $1 \%, 3$ times daily. In addition, oral doxycycline $100 \mathrm{mg}$ two times a day and oral vitamin $\mathrm{C}$ $500 \mathrm{mg}$ two times a day was also prescribed. Dua's classification was used to grade chemical injuries based on limbal and conjunctival involvement. All injuries up to grade 3 were treated conservatively and severe ocular injury of grade 4 and above, having guarded to poor prognosis underwent amniotic membrane transplantation under local anesthesia. Informed consent was obtained after explanation of the procedure. Amniotic membrane covered the whole ocular surface from lid margin to lid margin, was spread on the surface of eye stromal side down, a symblepharon ring of appropriate size was fitted over it. Edges of amniotic membrane after trimming were sutured to lid margins with 10/0 nylon. Bandage contact lens was applied to all eyes after the surgery. Postoperatively all patients received the same treatment and steroids were tapered down.

\section{Follow Up}

Follow up till a minimum period of 6 months was done. In all cases, weekly follow ups were done for the first month and visual acuity was recorded in every case. In each follow up, detailed slit lamp examination was carried out for improvement in limbal and conjunctival involvement, symblepharon formation, fornix foreshortening with ankyloblepharon. Development of superficial corneal vascularization, secondary glaucoma and uveitis in grade 4 and above chemical injuries was ruled out. Patients with limbal stem cell deficiency and symblepharon underwent subsequent surgeries like SLET (Simple Limbal Stem Cell Transplantation), symblepheron release after the inflammation subsided, respectively.

\section{Inclusion Criteria}

- All patients who presented to the ophthalmology department with chemical injury

- All genders and age

\section{Exclusion Criteria}

All other than chemical burn causing of traumatic abrasion or epithelial defects. 


\section{Observation and Results}

In all, 14 patients were men $(73.6 \%)$ and five were women $(26.3 \%)$. The most common etiological agent was alkali [73.6\%] other being acidic injury [26.3\%]. Injury was accidental in all cases, more in age group of 10 to 20 years comprising of $68.3 \%$ cases.

$52.6 \%$ patients had injury in both eyes (Fig. 1 and 2), rest $47.3 \%$ had injury in one eye (Fig. 3).

All injuries were graded according to Dua's classification. 3.4\% eyes suffered grade 1 chemical injury, with no limbal or conjunctival involvement. 55.1\% eyes had grade 2 chemical injury, involving up to or less than 3 clock hours and conjunctival involvement upto or less than $30 \%$. Grade 3 injury comprised of $>3$ to 6 clock hours of limbal involvement and $>30-50 \%$ of conjunctival involvement, found in $27.5 \%$ eyes. $10.3 \%$ eyes suffered grade 4 injuries with $>6$ to 9 clock hours of limbal involvement and $>50-75 \%$ of conjunctival involvement. Grade 5 injuries had $>9$ to $<12$ clock hours of limbal involvement and $>75-<100 \%$ of conjunctival involvement, seen in 3.4\% eyes. None of the grade 6 injuries were found in this study which comprises of total limbal involvement with $100 \%$ conjunctival involvement (Table 1-3).

Epithelial defect was graded as $<80 \%$ found in cases $17.1 \%$ eyes, $68.8 \%$ had $80-90 \%$ involvement and rest $>90 \%$ seen $13.7 \%$ eyes.

Medical management was continued $86.8 \%$ eyes in grade 1, grade 2, grade 3 injuries. Grade 4, grade 5 constituting $13.7 \%$ were surgically managed with amniotic membrane transplantation (Fig. 4) Amniotic membrane disintegrated on its own over a period of 7-20 days (Table 4-8).

At presentation, $>1 / 60$ vision was present in $37.8 \%$ eyes. $34.4 \%$ eyes had vision $1 / 60,24.1 \%$ cases had finger counting close to face. $3.4 \%$ cases were PL positive at presentation.

The mean follow-up after the injury was 6 months. Vision at the end of treatment improved up to $6 / 18$ in $3.4 \%$ eyes , $6 / 12$ in $3.4 \%$ eyes , up to $6 / 9$ in $30.9 \%$ eyes and $6 / 6$ in $62 \%$ eyes.

Epithelial defects of 58.5\% eyes healed within 1 month, $27.5 \%$ eyes healed in 2 month. $10.3 \%$ had persistent epithelial defects at the end of 2 months that took another 15 days to heal. $3.4 \%$ eyes with grade 5 injury took 4 months to heal. The duration of epithelial defect healing was significantly faster in grade 2 and 3 burns compared with the group with grade 4 burns. None of the patients developed corneal perforation (Table 9).

Symblepharon was graded as mild, moderate and severe. Cases with fornix foreshortening and horizontal involvement less than $25 \%$ were graded as mild, $25-50 \%$ involvement as moderate, and greater than this as severe. Symblepharon was seen in $6.8 \%$ eyes, out of which $3.4 \%$ with alkali burns having Grade 3 developed mild symblepharon, no reported cases of moderate symblepharon and $3.4 \%$ eyes having severe symblepharon was seen. Superficial corneal vascularization as an indicator of limbal stem cell deficiency was seen in $6.8 \%$ eyes.

Superficial corneal vascularization as an indicator of limbal stem cell deficiency was seen in $6.8 \%$ eyes having severe burns. $3.4 \%$ eyes of Grade 4 burns had 3 clock hour and $3.4 \%$ eyes

Thatte S | Volume 2; Issue 3 (2021) | JOAR-2(3)-020 | Research Article

Citation: Thatte S, et al. Outcome of Immediate Management in Chemical Ocular Burns. J Ophthalmol Adv Res. 2021;2(3):1-13.

DOI: http://dx.doi.org/10.46889/JOAR.2021.2301 
of grade $\mathrm{V}$ burns had 8-12 clock hour of superficial corneal vascularization encroaching till the center. None of the eyes developed secondary glaucoma or uveitis (Table 10).

\begin{tabular}{|c|c|c|c|c|}
\hline Age group & Males & Females & Alkali Injury & Acid Injury \\
\hline$<10$ years & 0 & $1[5.2 \%]$ & 2 eyes [6.9\%] & 0 eyes \\
\hline $10-20$ years & $10[52.6 \%]$ & $3[15.7 \%]$ & 11 eyes [38\%] & 7 eyes [24.1\%] \\
\hline $21-30$ years & 0 & $1[5.2 \%]$ & 2 eyes [6.9\%] & 0 eyes \\
\hline $31-40$ years & $1[5.2 \%]$ & 0 & 1 eyes [3.4\%] & 0 eyes \\
\hline $41-50$ years & $1[5.2 \%]$ & 0 & 2 eyes [6.9\%] & 0 eyes \\
\hline $51-60$ years & $2[10.5 \%]$ & 0 & 2 eyes [6.9\%] & 2 eyes [6.9\%] \\
\hline Total & $14[73.6 \%]$ & $5[26.3 \%]$ & 20 eyes [69\%] & 9 eyes [31\%] \\
\hline
\end{tabular}

Table 1: Clinical data of patients on the basis of age, sex and agent causing injury.

\begin{tabular}{|c|c|c|}
\hline Nature of Injury & Alkali Injury & Acid Injury \\
\hline Domestic & 14 eyes [48.3\%] & 7 eyes [24.1\%] \\
\hline Work related & 8 eyes [28\%] & 2 eyes [6.9\%] \\
\hline Total & 20 eyes [69\%] & 9 eyes [31\%] \\
\hline
\end{tabular}

Table 2: Clinical data of patients on the basis of mode of injury.

\begin{tabular}{|c|c|c|}
\hline & Alkali & Acid \\
\hline Unilateral & $8[\mathrm{n}=8$ eyes $]$ & $1[\mathrm{n}=1$ eyes $]$ \\
\hline Bilateral & $6[\mathrm{n}=12$ eyes] & $4[\mathrm{n}=8$ eyes $]$ \\
\hline Total & $14[\mathrm{n}=20$ eyes $]$ & 5 eyes $[\mathrm{n}=9$ eyes $]$ \\
\hline
\end{tabular}

Table 3: Laterality on the basis of agent causing injury. 


\begin{tabular}{|c|c|c|c|c|}
\hline $\begin{array}{c}\text { Grade of } \\
\text { Injury }\end{array}$ & Limbal Involvement & $\begin{array}{c}\text { Conjunctival } \\
\text { Involvement }\end{array}$ & Alkali & Acid \\
\hline Grade 1 & 0 clock hours & $0 \%$ & 0 eyes & 1 eyes [3.4\%] \\
\hline Grade 2 & $</=3$ clock hours & $</=30 \%$ & 11 eyes [37.9\%] & 5 eyes [17.3\%] \\
\hline Grade 3 & $>3$ to 6 clock hours & $>30-50 \%$ & 5 eyes [17.2\%] & 3 eyes [15.7\%] \\
\hline Grade 4 & $>6$ to 9 clock hours & $>50-75 \%$ & 3 eyes $[10.3 \%]$ & 0 eyes \\
\hline Grade 5 & $>9$ to $<12$ clock hours & $>75-<100 \%$ & 1 eyes [3.4\%] & 0 eyes \\
\hline Grade 6 & Total limbal involvement & $100 \%$ & 0 eyes & 0 eyes \\
\hline & Total & Total & 20 eyes [68.9\%] & 9 eyes [31.0\%] \\
\hline
\end{tabular}

Table 4: Grades of injury according to Dua's classification including degree of limbal [clock hours] and conjunctival involvement on the basis of agent causing injury.

\begin{tabular}{|c|c|c|}
\hline Epithelial Defect & Alkali & Acid \\
\hline$<80 \%$ & 4 eyes [13.7\%] & 1 eyes [3.4\%] \\
\hline $80-90 \%$ & 12 eyes [41.3\%] & 8 eyes [27.5\%] \\
\hline$>90 \%$ & 4 eyes [13.7\%] & 0 eye \\
\hline Total & 20 eyes[69\%] & 9 eyes [31\%] \\
\hline
\end{tabular}

Table 5: Percentage of epithelial defect based on agent causing injury.

\begin{tabular}{|c|c|c|}
\hline & Alkali & Acid \\
\hline Medical Management & 16eyes [55.8\%] & 9eyes [31\%] \\
\hline Surgical Management & 4 eyes [13.7\%] & 0eyes \\
\hline Total & 20 eyes [69\%] & 9 eyes [31\%] \\
\hline
\end{tabular}

Table 6: Mode of treatment on the basis of agent causing injury. 


\begin{tabular}{|c|c|c|}
\hline Presentation & Alkali & Acid \\
\hline PL positive & 1 eyes [3.4\%] & eyes \\
\hline $\begin{array}{c}\text { FCCF (finger counting close } \\
\text { to face) }\end{array}$ & 4 eyes [13.8\%] & 3 eyes [10.3\%] \\
\hline $1 / 60$ & 5 eyes [17.2\%] & 1 eyes [17.2\%] $[3.4 \%]$ \\
\hline$>1 / 60$ & 10 eyes [34.4\%] & 9eyes [31\%] \\
\hline Total & 20 eyes [69\%] & \\
\hline
\end{tabular}

Table 7: Visual acuity at presentation in alkali and acid burns.

\begin{tabular}{|c|c|c|}
\hline $\begin{array}{c}\text { Vision at the End of } \\
\text { Treatment }\end{array}$ & Alkali & Acid \\
\hline $6 / 18$ & 1 eyes [3.4\%] & 0eyes \\
\hline $6 / 12$ & 1 eyes [3.4\%] & 0eyes \\
\hline $6 / 9$ & 4 eyes [13.7\%] & 5 eyes [17.2\%] \\
\hline $6 / 6$ & 14 eyes [48.3\%] & 4 eyes [13.7\%] \\
\hline Total & 21 eyes [68.9\%] & 9 eyes [31\%] \\
\hline
\end{tabular}

Table 8: Visual acuity at the end of treatment in alkali and acid burns.

\begin{tabular}{|c|c|c|}
\hline Epithelial Defect Healing & Alkali & Acid \\
\hline Within 1 month & 11 eyes [37.9\%] & 6 eyes [20.6\%] \\
\hline Within 2 months & 5 eyes [17.2\%] & 3 eye [10.3\%] \\
\hline $2-2.5$ months & 3 eyes [10.3\%] & 0 eyes \\
\hline $3-4$ months & 1 eye [3.4\%] & 9 eyes [31\%] \\
\hline Total & 20 eyes [68.9\%] & \\
\hline
\end{tabular}

Table 9: Period of epithelial defect healing in alkali and acid burns. 


\begin{tabular}{|c|c|c|}
\hline Complication & Alkali & Acid \\
\hline Symblepharon & 2 eyes [6.8\%] & 0 eyes \\
\hline Stem cell loss & 2 eyes [6.8\%] & 0 eyes \\
\hline Total & 4 eyes [13.6\%] & 0eyes \\
\hline
\end{tabular}

Table 10: Complications in acute chemical burn in alkali and acidic burns.
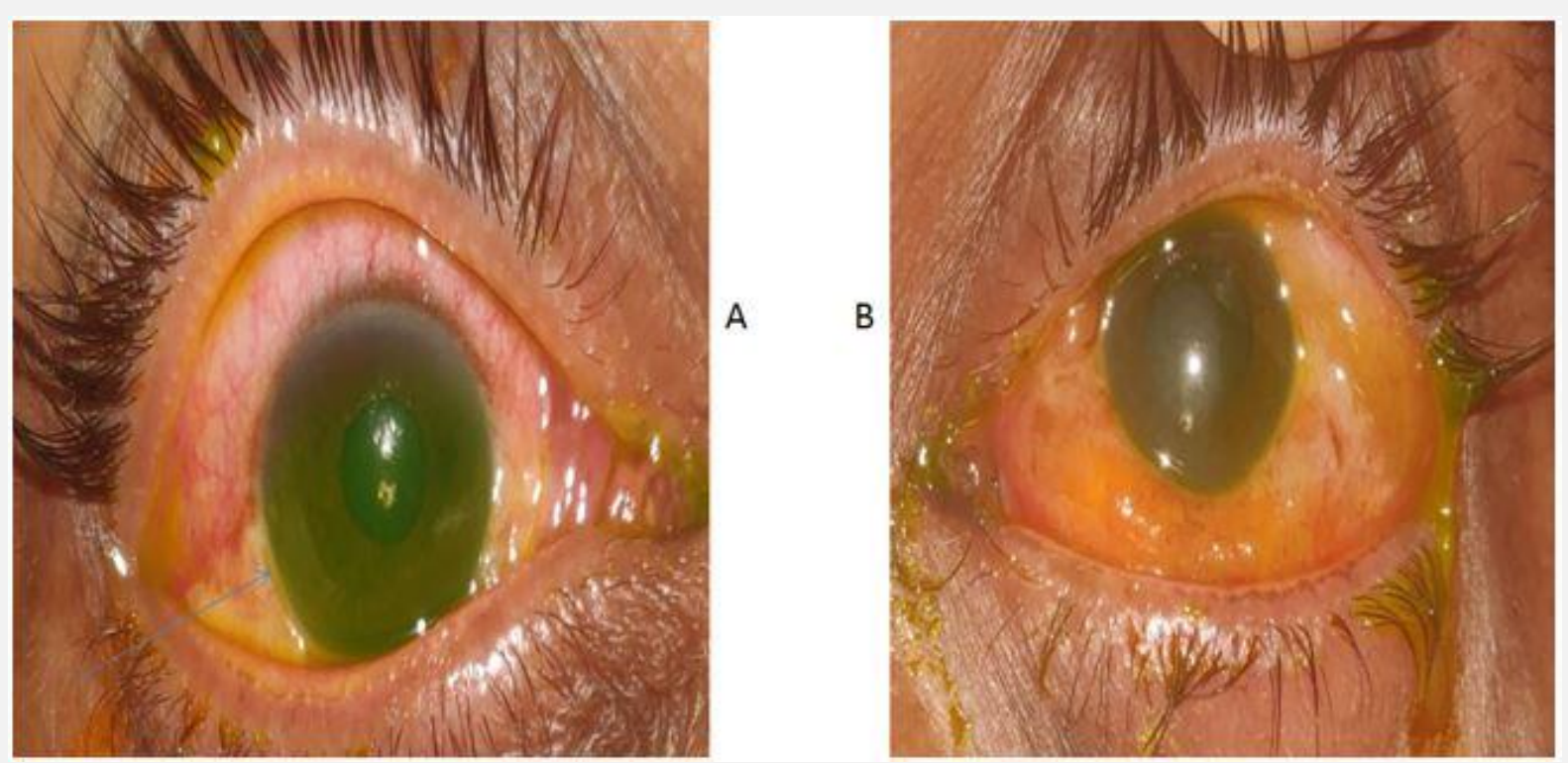

Figure 1: Showing bilateral chemical ocular injury. (A): Right eye grade 2 ocular chemical surface burn with $<3$ clock hours of limbal involvement, $30 \%$ conjunctival involvement, $<80$ epithelial defect. (B): Grade 2 ocular chemical surface burn with $<3$ clock hours of limbal involvement, $40 \%$ conjunctival involvement, $<80 \%$ epithelial defect.

Thatte S | Volume 2; Issue 3 (2021) | JOAR-2(3)-020 | Research Article

Citation: Thatte S, et al. Outcome of Immediate Management in Chemical Ocular Burns. J Ophthalmol Adv Res. 2021;2(3):1-13. 

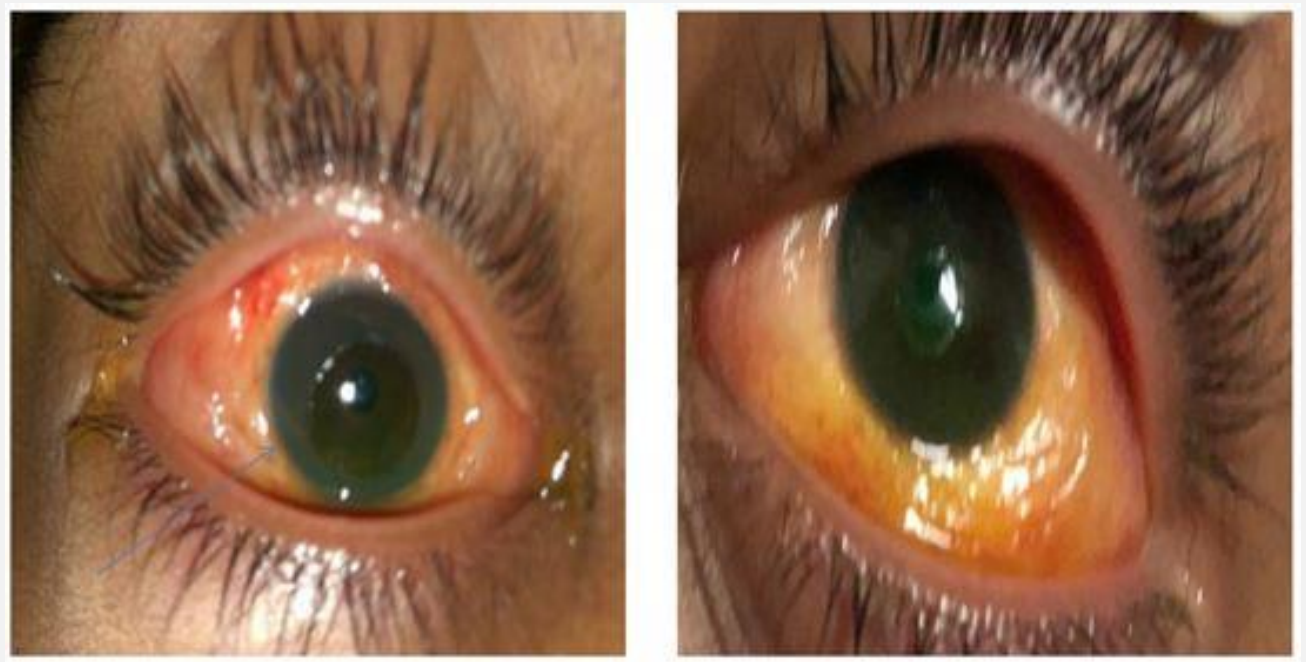

Figure 2: Showing bilateral chemical ocular injury. (A): Right eye grade 2 ocular chemical surface burn with $<3$ clock hours of limbal involvement, $40 \%$ conjunctival involvement, $<80$ epithelial defect. (B): Grade 3 injury with prelimbal ischemia from 5 o'clock to 7 o'clock and 10 o'clock to 3 o'clock ocular chemical surface burn with $<3$ clock hours of limbal involvement, $80 \%$ conjunctival involvement, $<60 \%$ epithelial defect.
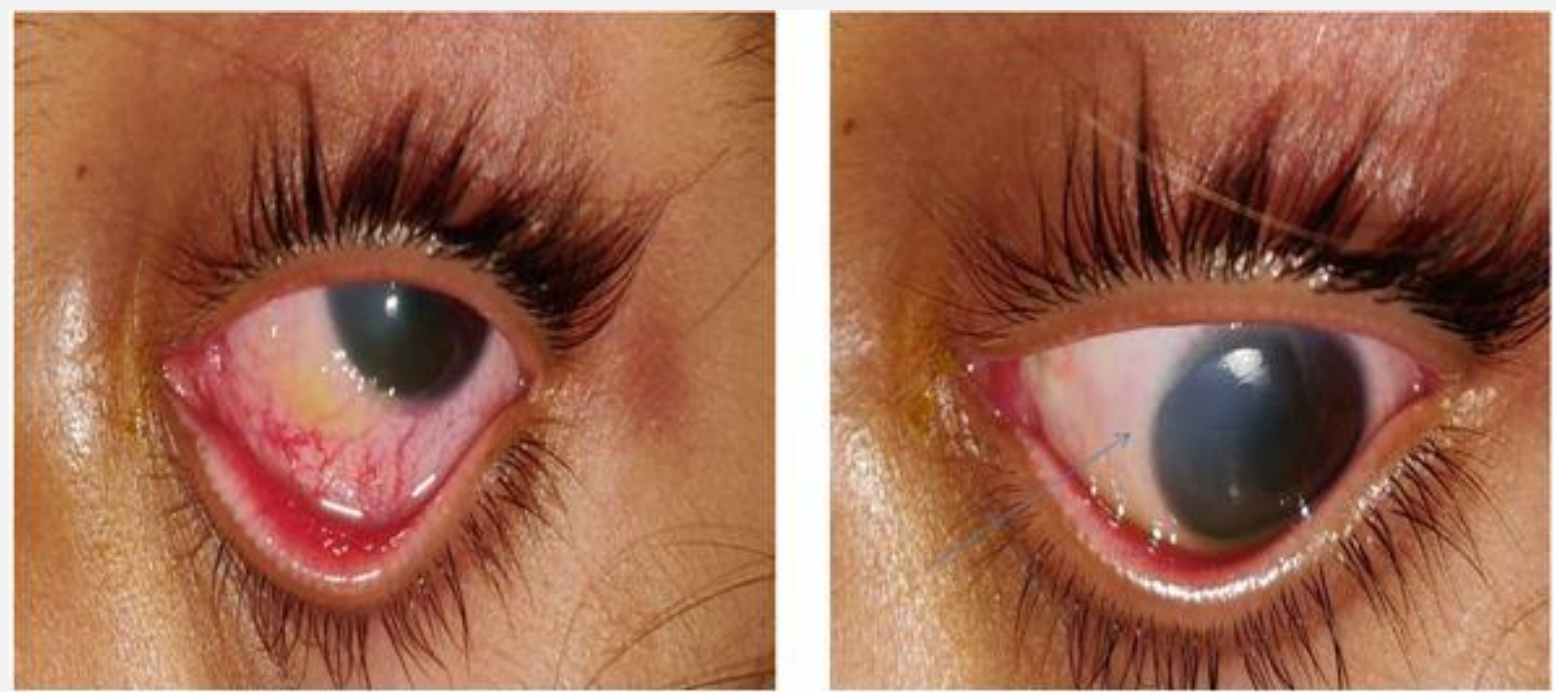

Figure 3: Showing unilateral alkaline ocular injury with grade 2 ocular chemical burn with 6 clock hours of limbal involvement, $50 \%$ conjunctival involvement, $<80 \%$ epithelial defect.

Thatte S | Volume 2; Issue 3 (2021) | JOAR-2(3)-020 | Research Article

Citation: Thatte S, et al. Outcome of Immediate Management in Chemical Ocular Burns. J Ophthalmol Adv Res. 2021;2(3):1-13. 


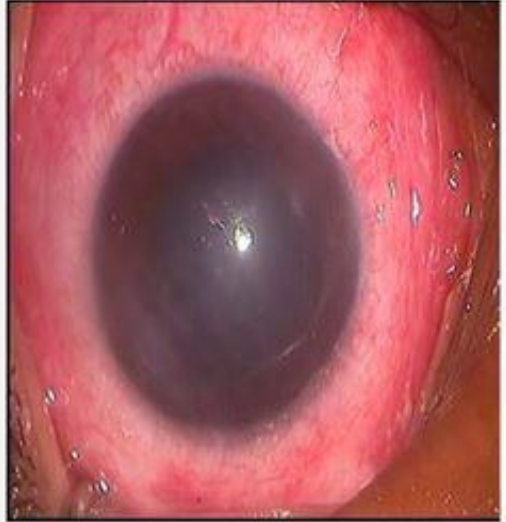

A



C
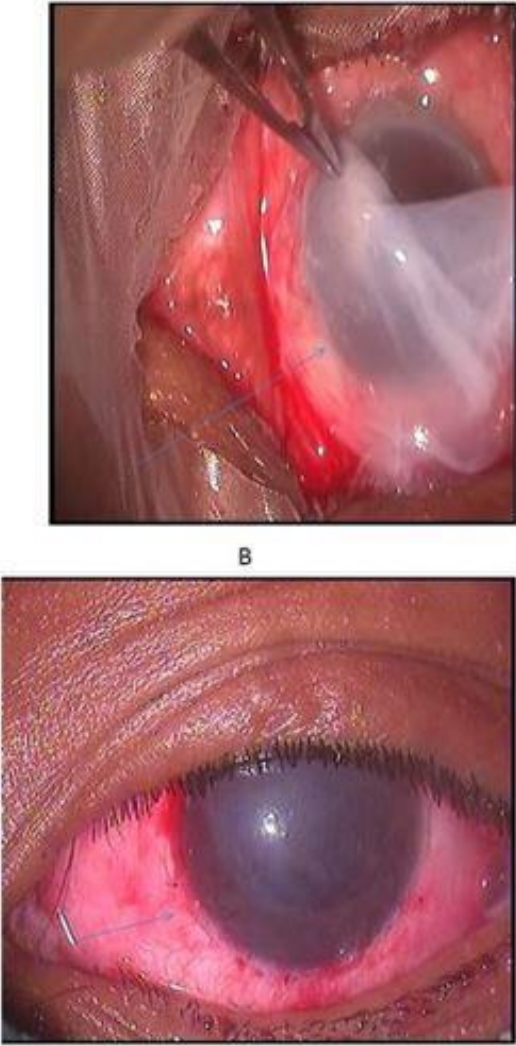

Figure 4: (A): Grade 4 ocular surface burn with, 9 clock hours of limbal involvement with 90\% conjunctival involvement, total epithelial defect. (B): Amniotic membrane covered the whole ocular surface from lid margin was spread on the surface of eye stromal side down.

(C): A symblepharon ring of appropriate size was fitted to prevent it in severe burns. (D):

Edges of amniotic membrane after trimming were sutured with 10/0 nylon.

\section{Discussion}

Ocular chemical injuries are associated with significant morbidity leading to vision loss and ocular surface damage. Appropriate management and intervention in the acute stage dictates the final outcome as well as the prognosis for visual rehabilitative procedures in chronic stage [4]. Classifying the parameters to be addressed in the acute stage and providing an algorithmic approach for managing the alterations in each of them will facilitate the primary goal of ensuring epithelization of the ocular surface [5].

We reported 29 eyes of 19 consecutive patients inflicted with acute chemical burns in the age group ranging from 6 years to 56 years. On gender distribution, other studies like done by Westekemper, et al., found male predominance which was similar to our study where incidence was $73.7 \%$ in males and $26.3 \%$ in females $[5,6]$.

Thatte S | Volume 2; Issue 3 (2021) | JOAR-2(3)-020 | Research Article

Citation: Thatte S, et al. Outcome of Immediate Management in Chemical Ocular Burns. J Ophthalmol Adv Res. 2021;2(3):1-13. 
All injuries found were accidental, more in young patients similar to Westekemper, et al., study in which data showed that young male patients in the working age group were more prone to have work-related chemical injuries, whereas young children tend to have domestic injuries [6]. Similar to other study we also observed alkali injury was commoner [6-9]. 52.6\% patients had injury in both eyes, rest $47.4 \%$ had injury in one eye [Fig. 3]. Bilateral involvement of eyes was observed more by Arora, et al., and others [6-9].

We graded injuries according to Dua's classification based on the observation of Gupta, et al., who found that the Dua classification has a superior prognostic predictive value [8].

It was noted by us as well others patients presented to the emergency department within hours of injury hence acute presentation was often seen [6-9].

Most of the ocular chemical injuries were grade 2, 55.1\%. Acidic injuries in our study were milder, with only up to grade 3 injuries. Compared to Ghosh, et al., where most of the injuries were grade $1,70.0 \%$, whereas grade 2 were $24.6 \%$ [9]. In both, our study as well as Ghosh, et al., the major percentage constituted mild to moderate injuries, and swift management was considered by copious irrigation and topical eye drops constituting steroids, ascorbic acid in alkali burns, antibiotics and cycloplegics [9].

The consideration for AMT in our study was taken up immediately the next day of injury in cases involving grade 4 and grade 5, similarly Ghosh, et al., considered AMT in grade 4 injuries and above [9]. In studies like Arora, et al., Westekemper, et al., Tamhane, et al., considered AMT in all cases within a period of 7-10 days irrespective of the grade, in agreement with observation that AMT supported epithelialization and rapid pain relief [6,7]. Arora, et al., found amniotic membrane transplantation protected against the progressive melting and perforation in grade 5 and above injuries [7]. Sharma, et al., compared AMT with conventional treatment in patients with mild to moderate chemical burns and found faster healing in patients undergoing AMT [9]. Similar to their observation, we also found patients undergoing AMT experienced a profound reduction of pain and photophobia. Furthermore, conjunctival scarring and limbal stem cell deficiency was not seen in grade 4 cases who received AMT [7].

In our study, mild and moderate cases were managed medically, due to early treatment and patient's compliance, swift recovery was seen and after 3 months, $62 \%$ eyes had $6 / 6$ vision, $30.9 \%$ eyes had 6/9. Epithelial defect healed completely within 2.5 months. These findings were similar to Ghosh, et al., where mild and moderate burns [94\%] treated medically gave good visual outcome of $6 / 9$ to $6 / 6$ and a completely healed epithelial defect within a similar month duration [9]. Arora, et al., found epithelial defects of $60 \%$ having mild to moderate burns healed within 8-10 weeks [7].

Whereas we recorded, $13.6 \%$ severe burns comprising of grade of 4 [10.3\%] and 5 [3.4\%] underwent AMT. The visual outcome in these eyes was good in $6.8 \%$ eyes who did not suffer any complication after AMT achieving a vision of 6/9. Rest $6.8 \%$ eyes with limbal stem cell deficiency, the vision fell back to $6 / 60$ in $3.4 \%$ eyes, epithelial defect took 3 months to heal and $5 / 60$ in other $3.4 \%$ eyes, with a healing span of 4 months of epithelial defect. In other

Thatte S | Volume 2; Issue 3 (2021) | JOAR-2(3)-020 | Research Article

Citation: Thatte S, et al. Outcome of Immediate Management in Chemical Ocular Burns. J Ophthalmol Adv Res. 2021;2(3):1-13.

DOI: http://dx.doi.org/10.46889/JOAR.2021.2301 
studies also, in grade 4, 5 and 6 injuries the visual outcome was average ranging from 1/60 to $6 / 60$, which may be due to late presentation, grievous insult with large limbal and conjunctival involvement [6-8].

It was our observation that $13.6 \%$ eyes suffered complications, constituting $6.8 \%$ eyes with symblepharon and $6.8 \%$ eyes with limbal stem cell deficiency in the form of corneal vascularization. All these eyes were associated with alkali injury, no eyes with acidic burn suffered any complication. $6.8 \%$ eyes had symblepharon, out of which $3.4 \%$ were mild seen with grade 3 injury and 3.4\% eyes suffered severe symblepharon, seen with grade 5 injury. In contrast to this, Arora, et al., in his study found symblepharon in $60 \%$ eyes, with a maximum share of $46.8 \%$ were associated with grade 4 burns having severe symblepharon [7]. Perhaps, comparing our study with Arora, et al., this difference in percentage might be due to large predominance of milder cases in our study, that too presenting early and receiving early treatment [7].

Mild symblepharon was seen in 3.4\% eyes, since there was no restriction of movement, hence we prescribed only topical lubricants and steroids. In other $3.4 \%$ eyes symblepharon tag was released after inflammation receded combined with SLET (Simple Limbal Epithelial Transplantation). Likewise, Arora, et al., managed milder cases in a similar fashion and for moderate and severe cases a secondary procedure of symblepharon release was performed after an average of two months period when the inflammation subsided [7].

We noted superficial corneal vascularization as an indicator of limbal stem cell deficiency in $6.8 \%$ eyes having severe alkali burns, out of which $3.4 \%$ eyes of Grade 4 burns had 3 clock hour and 3.4\% eyes of grade $\mathrm{V}$ burns had 8-12 clock hour of superficial corneal vascularization encroaching till the center. Similarly, $6 \%$ eyes LSCD (Limbal Stem Cell Deficiency) was seen by Ghosh, et al., in grade 5 injuries and the $7.7 \%$ eyes were documented by Morgan [9]. In study by Arora, et al., 53.6\% eyes of grade IV burns 8-12 clock hour of superficial corneal vascularization, thus correlating severity of corneal vascularization with severity of chemical burn, as majority of cases that constituted in his study were severe burns [11,12].

We performed SLET in $6.8 \%$ eyes, out of which $3.4 \%$ eyes underwent a combined symblepharon release with SLET, after 2 months when the inflammation resolved. Visual outcome was enhanced from $5 / 60$ to $6 / 18$ postoperatively. In other $3.4 \%$ eyes SLET was performed after one month and the visual outcome improved to 6/12 vision from 6/60. This can be correlated well with studies by Ghosh, et al., Morgan, et al., and Arora, et al., as, where limbal stem cell transplantation was performed subsequently as the inflammation subsided within a period of 3 months, with a fair visual outcome postoperatively $[7,9,10,12]$.

\section{Conclusion}

In conclusion, the data presented in our study show that young male patients in the working age group are more prone to have work-related chemical injuries, whereas young children tend

Thatte S | Volume 2; Issue 3 (2021) | JOAR-2(3)-020 | Research Article

Citation: Thatte S, et al. Outcome of Immediate Management in Chemical Ocular Burns. J Ophthalmol Adv Res. 2021;2(3):1-13.

DOI: http://dx.doi.org/10.46889/JOAR.2021.2301 
to have domestic injuries. In addition, Dua's classification seems to have a prognostic value, especially in the most severe cases. Alkali was the most common causative agent involved. Fortunately, most of the ocular chemical injuries that were seen in were minor, and with prompt and brisk continuous irrigation of the ocular surface, and subsequent intensive topical treatment improvement in symptoms, appreciable visual outcome and patient satisfaction was seen in all cases. Segregation of cases requiring medical or surgical management was wisely undertaken that ensued additional benefit. Consistent follow ups by the patient helped in identifying subsequent sequelae in severe burns, and a forethought planned approach for further surgeries, with an appropriate waiting period was made, aiding in meticulously managing the complications as well for a better prognosis.

\section{References}

1. Reim M, Kuckelkorn R. Verätzungen und Verbrennungen der Augen. Akt Augenheilkd. 1995;20:76-89.

2. Renard G. Physiopathology of eye burns. J Fr Ophtalmol. 2004;27:1164-9.

3. Gupta A, Kalaivani M, Tandon R. Comparison of prognostic value of Roper Hall and Dua classification systems in acute ocularburns. Br J Ophthalmol. 2011;95:194-8.

4. Singh P, Tyagi M, Kumar Y, Gupta KK, Sharma PD. Ocular chemical injuries and their management. Oman J Ophthalmol. 2013;6(2):83-6.

5. Kwok JM, Chew HF. Chemical injuries of the eye. CMAJ. 2019;191(37):E1028.

6. Westekemper H, Figueiredo FC, Siah WF, Wagner N, Steuhl KP, Meller D. Clinical outcomes of amniotic membrane transplantation in the management of acute ocular chemical injury. $\mathrm{Br} \mathrm{J}$ Ophthalmol. 2016;101(2):103-7.

7. Arora R, Mehta D, Jain V. Amniotic membrane transplantation in acute chemical burns. Eye. 2005;19(3):2738 .

8. Ghosh S, Salvador-Culla B, Kotagiri A, Pushpoth S, Tey A, Johnson ZK, et al. Acute chemical eye injury and limbal stem cell deficiency-a prospective study in the United Kingdom. Cornea. 2019;38(1):8-12.

9. Morgan SJ. Chemical burns of the eye: causes and management. Br J Ophthalmol. 1987;71:854-7.

10. Sharma N, Kaur M, Agarwal T, Sangwan VS, Vajpayee RB. Treatment of acute ocular chemical burns. Surv Ophthalmol. 2018;63(2):214-35.

11. Au SCL. Hand sanitizer associated ocular chemical injury: A mini-review on its rise under COVID-19. Vis J Emerg Med. 2020;21:100881.

12. Dua HS, Ting DSJ, Al Saadi A, Said DG. Chemical eye injury: pathophysiology, assessment and management. Eye (Lond). 2020;34(11):2001-19.

Thatte S | Volume 2; Issue 3 (2021) | JOAR-2(3)-020 | Research Article 